\title{
Evaluation of Cooking Time of Chicken Patties Prepared Using Woody Broiler Breast Meat
}



\author{
Juan P. Caldas-Cueva ${ }^{1}$, Aline Giampietro-Ganeco ${ }^{2}$, and Casey M. Owens ${ }^{1 *}$ \\ ${ }^{1}$ Department of Poultry Science, University of Arkansas, Fayetteville, AR 72701, USA \\ ${ }^{2}$ Department of Food Engineering, University of São Paulo - USP, Pirassununga, São Paulo, Brazil \\ *Corresponding author. Email: cmowens@uark.edu (Casey M. Owens)
}

\begin{abstract}
This study evaluated the cooking time of chicken patties prepared with broiler breast fillets exhibiting varying degrees of woody breast (WB). Intact breast fillets $(n=90)$ deboned at $3 \mathrm{~h}$ postmortem were collected from broilers processed following commercial-based operations and categorized based on the degree of tactile hardness in $3 \mathrm{WB}$ categories (normal [NOR], mild [MIL], and moderate/severe [SEV]). These tactile scores were validated using the instrumental compression force analysis. Fillet color $\left(L^{*}, a^{*}\right.$, and $\left.b^{*}\right)$ and $\mathrm{pH}$ were also measured at $24 \mathrm{~h}$ postmortem. Breast fillets were individually ground and formed into patties (patties made with NOR [P-NOR], patties made with MIL [P-MIL], and patties made with SEV [P-SEV]). Patties were cooked from $2^{\circ} \mathrm{C}$ to a final center temperature of $75^{\circ} \mathrm{C}$ on a flat electric griddle $\left(150^{\circ}\right.$ C). Internal patty temperatures were measured at $0,1,2,3$, and $4 \mathrm{~min}$ and then every $30 \mathrm{~s}$ until the target core temperature was reached. Cook loss and moisture content were also evaluated in cooked patties. SEV fillets showed higher $(P<0.05)$ compression force, $\mathrm{pH}, L^{*}, a^{*}$, and $b^{*}$ values than NOR fillets. The cooking time to the terminal point was lower for P-SEV compared with P-NOR $(P<0.05)$. No differences were observed in cooking time between P-MIL and the other patty samples. Cook loss and moisture content levels were greater $(P<0.05)$ in P-SEV in comparison with P-NOR and P-MIL. These results suggest that the WB condition can alter the thermal processing of chicken patties by reducing the cooking time. Further research would be needed to confirm potential alterations caused by this myopathy in thermophysical properties of intact WB fillets and further processed poultry products containing WB meat.
\end{abstract}

Key words: woody breast, myopathy, meat quality, poultry product, thermal processing

Meat and Muscle Biology 5(1): 8, 1-8 (2021) doi:10.22175/mmb.11690

Submitted 23 October $2020 \quad$ Accepted 15 January 2021

\section{Introduction}

It is evident that the global consumption of precooked poultry products has increased consistently over the years. This increasing demand has driven an intensive study of thermal processes in determining the safety, quality, and yield of commercial poultry meat products such as chicken patties (Chen et al., 1999; Murphy et al., 2001a, 2001b; Isleroglu et al., 2014; Ferreira et al., 2018). Pan-frying, grilling, and pan-broiling could be considered common cooking techniques by which patties are cooked by direct heat conduction, which involves heat transfer by contact between the preheated surface and the meat product (Bejerholm et al., 2014).
Indeed, the temperature on the surface of the meat product, the temperature profile through the meat product, and the method of heat transfer are major factors that differ among cooking methods (Isleroglu et al., 2014). From these key components, cooking time is an important processing and economic factor for the industry, which can be significantly affected by product temperature and cooking conditions (Murphy et al., 2001a, 2001b). The cooking time required for a product to reach the targeted core temperature depends on the properties of the product in addition to the cooking conditions (Murphy et al., 2001a). In this sense, any quality impairment of the meat used in the product formulation could influence the cooking time. 
One of the main meat quality problems in the modern poultry industry is the woody breast (WB) condition, which is primarily characterized by a noticeable hardness in broiler breast muscles exhibiting histopathological, morphometric, and physicochemical alterations that result in unwanted sensorial, nutritional, and technological properties (Sihvo et al., 2014; Soglia et al., 2016a, 2016b; Baldi et al., 2019; Petracci et al., 2019). These negative implications coupled with considerable occurrence rates can result in important economic losses (Baldi et al., 2020a; Caldas-Cueva and Owens, 2020). Thus, one of the most urgent challenges is the development of profitable options for industrial utilization of WB meat such as its application in further processed poultry products (Petracci et al., 2019; Caldas-Cueva and Owens, 2020). In fact, recent studies have evaluated quality and sensory characteristics of commercial poultry meat products made from WB meat (Sanchez-Brambila et al., 2017; Madruga et al., 2019; Santos et al., 2019; Caldas-Cueva et al., 2020a, 2020b; Jarvis et al., 2020). Additionally, functional properties of WB meat batters have been studied (Xing et al., 2017; Chen et al., 2018; Zhang et al., 2020). However, further research is still needed to understand the impact of using chicken meat at varying degrees of WB severity on important indicators such as the cooking time of poultry meat products. In this context and considering that no research has been published related to the effect of the WB condition on thermal properties, this study aimed to assess the cooking time of chicken patties prepared using broiler breast fillets at different degrees of WB severity.

\section{Materials and Methods}

\section{Sample collection}

Boneless and skinless breast fillets were collected from commercial 8-wk-old broilers (high breast-yielding strain) processed at the University of Arkansas Poultry Processing Pilot Plant following commercialbased operations (Mehaffey et al., 2006). These breast fillets were scored for the degree of hardness using the palpation method proposed by Tijare et al. (2016). The WB categorization considered in this experiment was as follows: normal breast fillets (NOR), mild WB or fillets partially affected by the WB condition (MIL), and fillets moderately or severely affected by the WB condition (SEV). After tactile scoring, instrumental compression force (CF) analysis, which is described later in the meat quality evaluation section, was carried out to validate subjective scores. From these hardness assessments, classified fillets ( 30 per WB group) were packed in zip-sealed plastic bags and stored overnight at $4^{\circ} \mathrm{C}$.

\section{Meat quality traits}

CF analysis was carried out on raw fillets by averaging 4 readings at predetermined points in the cranial area of each fillet using a texture analyzer (Model TA.XT Plus, Texture Technologies Corp., Scarsdale, NY). Fillets were compressed to $20 \%$ of their initial height with a $6-\mathrm{mm}$ diameter flat probe using a $5-\mathrm{kg}$ loading cell and settings of trigger force of $5 \mathrm{~g}$ and a test speed of $5 \mathrm{~mm} / \mathrm{s}$ (Sun et al., 2018; Caldas-Cueva et al., 2020a, 2020b). Color measurements (Commission Internationale de 1'Eclairage ["International Commission on Illumination"] $L^{*}=$ lightness, $a^{*}=$ redness, and $b^{*}=$ yellowness) were obtained in triplicate from the dorsal surface of each fillet using a calibrated colorimeter (Model CR-400, Konica Minolta Sensing Inc., Osaka, Japan). The color values from the 3 readings per fillet were averaged automatically by the instrument before further use. The $\mathrm{pH}$ was measured at the cranial end area of each fillet using a portable $\mathrm{pH}$ meter (Model Testo 205, Testo Inc., Sparta, NJ). Both muscle $\mathrm{pH}$ and color were measured at $24 \mathrm{~h}$ postmortem.

\section{Preparation of patties}

Three chicken patty treatments (patties prepared with NOR [P-NOR], patties prepared with MIL [PMIL], and patties prepared with SEV [P-SEV]) were prepared using broiler breast fillets that were randomly selected from each WB category group (NOR, MIL, and SEV; $n=20$ fillets per category/treatment) as described in Table 1 . The preparation of 1 patty sample per treatment using an individual fillet was considered a replicate. The whole cranial section of each breast fillet was cut, trimmed to remove all visible excess of fat, and then ground individually using an electric meat

Table 1. Chicken patties prepared using broiler breast fillets exhibiting varying degrees of WB severity

\begin{tabular}{ll}
\hline \hline Treatment & \multicolumn{1}{c}{ Description } \\
\hline P-NOR & $\begin{array}{l}\text { Patties prepared using 100\% of normal or unaffected broiler } \\
\text { breast meat }\end{array}$ \\
P-MIL & $\begin{array}{l}\text { Patties prepared using 100\% of broiler breast meat partially } \\
\text { or mildly affected by WB condition }\end{array}$ \\
P-SEV & $\begin{array}{l}\text { Patties prepared using 100\% of broiler breast meat } \\
\text { moderately or severely affected by WB condition }\end{array}$ \\
\hline
\end{tabular}

$\mathrm{MIL}=$ mild $\mathrm{WB} ; \mathrm{NOR}=$ normal breast; $\mathrm{P}=$ patty; $\mathrm{SEV}=$ moderate or severe $\mathrm{WB} ; \mathrm{WB}=$ woody breast. 
grinder (Chefmate, CC12; GFE, Dayton, $\mathrm{OH}$ ) through a 3-mm plate. Eighty-five grams of each ground breast meat was manually formed into a uniform circularshaped patty (diameter: $87 \mathrm{~mm}$ and thickness: 15 $\mathrm{mm}$ ) using a plastic Petri dish. Subsequently, raw chicken patty samples were separately vacuum packed $\left(20 \mathrm{~mm} \mathrm{Hg}\right.$ ) and stored at $-22^{\circ} \mathrm{C}$ for no more than $4 \mathrm{~d}$ until cooking for further analysis.

\section{Cooking procedure}

Frozen patty samples were thawed overnight at $2^{\circ} \mathrm{C}$ and then cooked on a preheated $\left(150^{\circ} \mathrm{C}\right) 20$-in electric griddle (Model 0705305; National Presto Industries Inc., Eau Claire, WI). Patties were turned at $3 \mathrm{~min}$ until their core temperature reached $75^{\circ} \mathrm{C}$. A 12-channel Digi-sense scanning thermometer (Model 69200-00; Barnant Co., Barrington, IL) was used to record internal patty temperatures at $0,1,2$, 3 , and $4 \mathrm{~min}$ and every $30 \mathrm{~s}$ after $4 \mathrm{~min}$ until the target end-point temperature was achieved. The recorded data were used to develop the time-temperature profile or history. Cooked patty samples were cooled to room temperature $\left(23^{\circ} \mathrm{C} \pm 2^{\circ} \mathrm{C}\right)$ and analyzed. Patties were weighed before cooking and after their removal from the heating surface and drainage on absorbent paper to calculate the percentage of cook loss based on raw patty weight. Subsequently, the moisture content in cooked samples ( $n=10 /$ treatment) was determined by the AOAC (2005) 950.46b method.

\section{Statistical analysis}

The results were statistically analyzed using JMP software, version 14.3.0 (SAS Institute Inc., Cary, $\mathrm{NC})$. The data were evaluated using one-way analysis of variance with WB category (NOR, MIL, SEV; for raw meat quality traits) or treatment factor (P-NOR, P-MIL, P-SEV; for cooking time, cook loss, and moisture content of chicken patties) fit as fixed effect.
Means were separated using the Tukey's honest significant difference test at $P<0.05$ when a significant main effect was observed.

\section{Results and Discussion}

\section{Meat quality traits}

The quality traits of raw broiler breast fillets were different among WB classes $(P<0.01)$, as presented in Table 2 . The WB condition altered meat quality characteristics by increasing $(P<0.05) \mathrm{CF}, \mathrm{pH}$, and lightness $\left(L^{*}\right)$ values as the severity of this myopathy increased in raw breast fillets. In addition, SEV fillets showed higher redness $\left(a^{*}\right)$ and yellowness $\left(b^{*}\right)$ values than MIL and NOR fillets $(P<0.05)$. These results confirm the impairment caused by WB in broiler meat quality, which has been widely supported by published data in the literature. Dalgaard et al. (2018), Sun et al. (2018), Caldas-Cueva et al. (2020a), and Caldas-Cueva et al. (2020b) reported that SEV chicken fillets showed higher weights as well as higher CF values compared with NOR fillets, which was also corroborated in this study, confirming the relationship of WB frequency with heavier breast muscles that may be related to the continuous selection of broilers for rapid muscle growth and greater yields (Sihvo et al., 2014; Velleman et al., 2019).

The fibrosis may explain the irregular hardness of WB meat; nevertheless, this pathological process could not be the sole cause of its hardening (Sihvo et al., 2014, 2017). Higher $\mathrm{pH}$ values have also been reported in SEV fillets compared with NOR fillets (SanchezBrambila et al., 2017; Dalgaard et al., 2018; Madruga et al., 2019), which may be linked to an altered energy-generating pathway coupled with a deficiency and/or dysfunction of muscle ATPases (Baldi et al., 2020b). On the other hand, even though scientists have not reported consistent instrumental color results of WB meat, some of them have highlighted that

Table 2. Meat quality traits of raw broiler breast fillets exhibiting varying degrees of WB severity

\begin{tabular}{|c|c|c|c|c|}
\hline \multirow[b]{2}{*}{ Parameter } & \multicolumn{3}{|c|}{ WB category ${ }^{1}$} & \multirow[b]{2}{*}{ SEM } \\
\hline & NOR & MIL & SEV & \\
\hline Fillet weight (g) & $385.40^{\mathrm{c}}$ & $431.90^{\mathrm{b}}$ & $476.13^{\mathrm{a}}$ & 6.71 \\
\hline Compression force $(\mathrm{N})$ & $4.19^{\mathrm{c}}$ & $9.27^{\mathrm{b}}$ & $16.64^{\mathrm{a}}$ & 0.35 \\
\hline $\mathbf{p H}$ & $5.73^{\mathrm{c}}$ & $5.81^{\mathrm{b}}$ & $6.01^{\mathrm{a}}$ & 0.02 \\
\hline Lightness $\left(L^{*}\right)$ & $54.58^{\mathrm{c}}$ & $56.41^{\mathrm{b}}$ & $58.21^{\mathrm{a}}$ & 0.39 \\
\hline Redness $\left(a^{*}\right)$ & $1.83^{\mathrm{b}}$ & $1.86^{\mathrm{b}}$ & $2.91^{\mathrm{a}}$ & 0.20 \\
\hline Yellowness $\left(b^{*}\right)$ & $12.98^{\mathrm{b}}$ & $13.19^{\mathrm{b}}$ & $14.59^{\mathrm{a}}$ & 0.29 \\
\hline
\end{tabular}

${ }^{\mathrm{a}-\mathrm{c}}$ Means within a row with no common superscripts differ significantly $(P<0.05)$.

$\mathrm{MIL}=$ mild $\mathrm{WB} ; \mathrm{NOR}=$ normal breast $\mathrm{SEV}=$ moderate or severe $\mathrm{WB} ; \mathrm{WB}=$ woody breast. 
SEV fillets were lighter, redder, and yellower than NOR fillets (Dalle Zotte et al., 2017; Cai et al., 2018). Differences in instrumental color outcomes found in the literature could be related to the heterogeneity of WB severity throughout the affected chicken breast fillet (Bowker et al., 2018; Wold et al., 2019; Caldas-Cueva et al., 2020a) as well as the occurrence of hemorrhages and viscous exudate on its surface (Sihvo et al., 2014; Dalle Zotte et al., 2017).

\section{Thermal profile and cooking time}

The time-temperature profile obtained for the chicken patty samples subjected to the cooking process are shown in Figure 1. Regardless of the treatment, the thermal profile of patties cooked on a preheated $\left(150^{\circ} \mathrm{C}\right)$ electric griddle followed a similar pattern (i.e., the center temperature of samples gradually increased with time); however, the curve became steeper as WB severity increased in the meat used for patty preparation. Moreover, temperature fluctuations between 3 and 4 min were more evident in PSEV in comparison with P-MIL and P-NOR. Although these temperature variations could be mainly explained by the fact that patties were flipped at $3 \mathrm{~min}$ of the cooking process, the higher fluctuation observed in P-SEV might be linked to chemical and histological modifications in muscle fibers and connective tissues caused by this abnormality (Soglia et al., 2016b). However, more research is needed to determine causes for this plateau between 3 and 4 min since this occurred at approximately $45^{\circ} \mathrm{C}$, well below a temperature that results in collagen denaturation or collagen shrinking (Tornberg, 2005). However, myofiber shrinking occurs

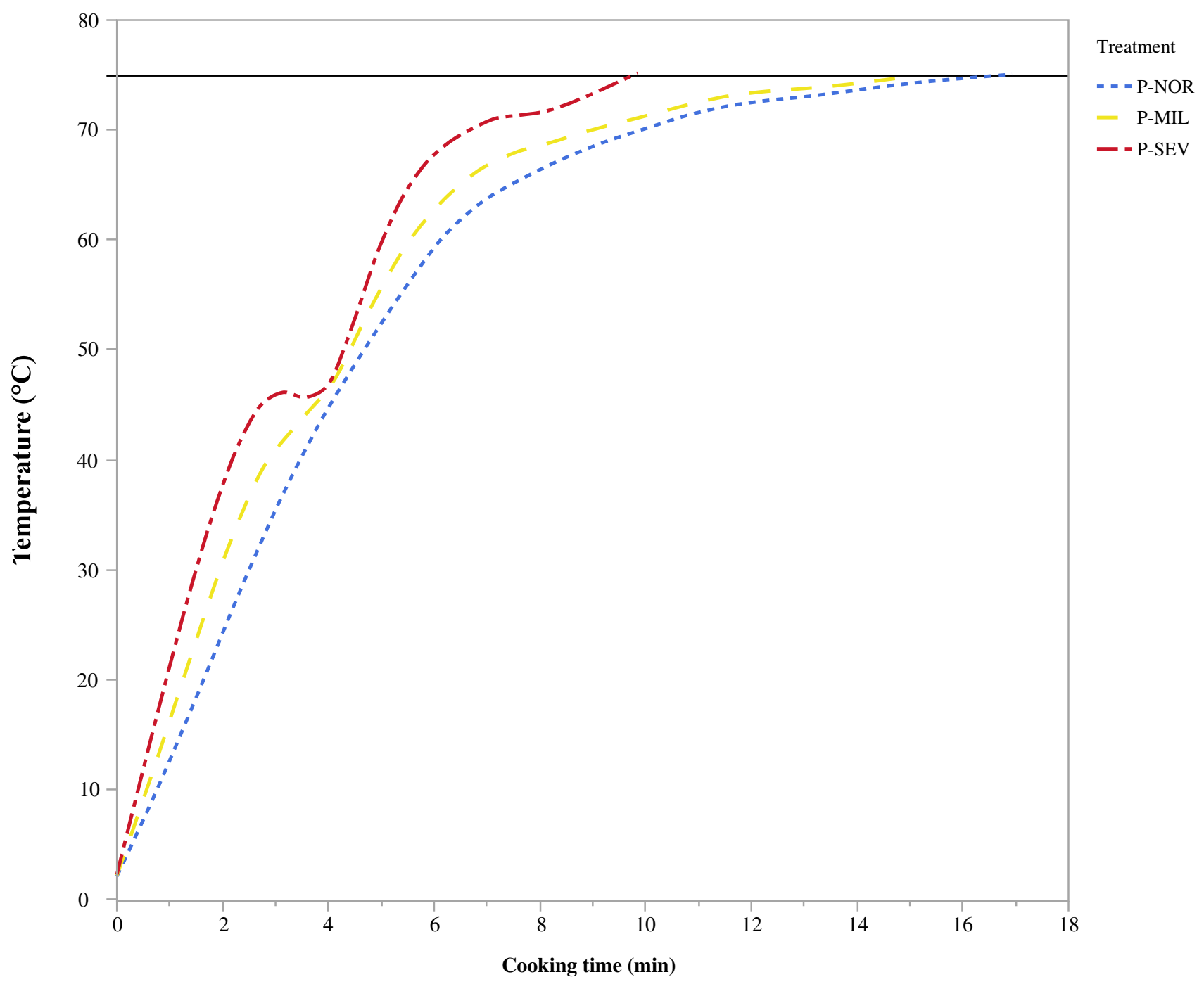

Figure 1. Time-temperature profile of chicken patties prepared using broiler breast fillets exhibiting varying degrees of WB severity. The profile was built using all time-temperature points from each replication $(n=20$ /treatment $)$ P-MIL $=$ mild WB patties; P-NOR $=$ normal breast patties; P-SEV $=$ moderate or severe WB patties; WB = woody breast. 
in this temperature range $\left(40^{\circ} \mathrm{C}-60^{\circ} \mathrm{C}\right)$ (Tornberg, 2005; Pathare and Roskilly, 2016), and it is possible that subsequent expulsion of water could have resulted in some evaporative cooling although the time period of the plateau was short $(<1 \mathrm{~min})$. WB has greater amount of moisture release as indicated by increased cook loss (Table 3), possibly leading to greater evaporative cooling than NOR samples would have experienced.

The results from this study showed that there were differences $(P<0.01)$ among chicken patty treatments in terms of cooking time (Table 3 ). The average cooking time of P-NOR $(10.85 \mathrm{~min})$ was higher $(P<0.05)$ than that for P-SEV (7.23 min). There was not a difference $(P>0.05)$ in cooking time between P-MIL and the other treatments. Nevertheless, these results suggest that the cooking time of chicken patties decreases as WB severity increases in the meat used in their preparation. In this sense, the heat transfer properties could be altered by the WB condition in chicken patties. Potential impaired thermal properties of P-SEV may be associated with the muscle fiber degeneration accompanied by lipidosis, fibrosis, and impairments in fiber membrane integrity caused by WB abnormality that derives in chicken meat with an altered composition (Soglia et al., 2016a, 2016b; Baldi et al., 2019) and muscle fiber number (Sihvo et al., 2014; Mazzoni et al., 2015), which in turn produces products more irregular and arranged in a more disorderly way compared with NOR samples (Xing et al., 2017). In addition, the accretion of interstitial matter such as water, collagen, and proteoglycans in WB meat (Sihvo et al., 2014; Petracci et al., 2019) might also contribute to explain these variations. From these last components, the water content that has been found at higher levels in SEV fillets compared with NOR fillets (Soglia et al., 2016a, 2016b; Baldi et al., 2019) may have a significant impact on the reduced cooking time of WB patties because some researchers have reported that processed meat and poultry products containing higher levels of moisture content were linked to higher values of thermophysical properties such as thermal conductivity and diffusivity (Marcotte et al., 2008).

\section{Cook loss}

The results associated with the effect of WB myopathy on cook-loss levels of chicken patty samples are also summarized in Table 3. The average cook loss for P-NOR $(17.06 \%)$ was lower $(P<0.05)$ than that for P-SEV (25.35\%). P-MIL also presented an average cook loss $(20.12 \%)$ that was lower $(P<0.05)$ than that for P-SEV; however, it was comparable to P-NOR. In contrast to the cooking time results, the cook-loss levels increased as WB severity increased in the breast fillet used for patty preparation. Indeed, recently published studies have reported that quality and yield loss differences were still detectable in chicken patties prepared using high proportions $(\geq 67 \%)$ of WB meat (Caldas-Cueva et al., 2020a; Jarvis et al., 2020). Bejerholm et al. (2014) suggest that the cook loss is determined by a combination of heating rate and cooking time, and the heat-induced changes in the meat structure can explain variations in cook loss. Considering that patty samples were treated under similar thermal processing conditions, higher cook-loss levels observed in P-SEV could be explained by the poor ability to hold water that has been widely attributed to WB fillets. Researchers have associated the poor water-holding capacity of WB meat with the histopathological, morphometric, and physicochemical impairments caused by this myopathy (Sihvo et al., 2014; Soglia et al., 2016a, 2016b; Baldi et al., 2019; Petracci et al., 2019). Although contrasting cook-loss results between products made from unaffected and WB fillets have been reported (Sanchez-Brambila et al., 2017; Xing et al., 2017; Chen et al., 2018; Madruga et al., 2019), the aforementioned alterations caused by WB defect would justify the significant increasing trends in cook loss observed in WB patties. After cooking, noticeable dimensional changes were also

Table 3. Effect of WB condition on cooking time, cook loss, and moisture content of chicken patties

\begin{tabular}{|c|c|c|c|c|}
\hline \multirow[b]{2}{*}{ Parameter } & \multicolumn{3}{|c|}{ Treatment $^{1}$} & \multirow[b]{2}{*}{ SEM } \\
\hline & P-NOR & P-MIL & P-SEV & \\
\hline Cooking time (min) & $10.85^{\mathrm{a}}$ & $8.92^{\mathrm{ab}}$ & $7.23^{b}$ & 0.57 \\
\hline Cook loss (\%) & $17.06^{\mathrm{b}}$ & $20.12^{\mathrm{b}}$ & $25.35^{\mathrm{a}}$ & 0.97 \\
\hline Moisture $^{2}(\%)$ & $67.10^{\mathrm{b}}$ & $68.12^{\mathrm{b}}$ & $70.05^{\mathrm{a}}$ & 0.38 \\
\hline
\end{tabular}


observed in P-SEV which are consistent with our preceding experiments (Caldas-Cueva et al., 2020a). Our previous studies have reported that chicken patties produced using SEV fillets-either alone or combined with MIL fillets-presented higher cook-loss levels $(>26 \%, P<0.05)$ along with significant reductions in diameter $(>16 \%, P<0.05)$ compared with patties made from NOR fillets (Caldas-Cueva et al., 2020a).

\section{Moisture content}

The amount of moisture lost during the cooking process of poultry products is important in terms of eating quality and product yield. Table 3 also shows the effect of the WB condition on moisture content of cooked chicken patties. The moisture content was higher $(P<0.05)$ in $\mathrm{P}-\mathrm{SEV}$ in comparison with $\mathrm{P}$ MIL or P-NOR, whereas no differences were observed in moisture content between P-NOR and P-MIL. Various studies have consistently reported higher levels of moisture content in SEV fillets compared with NOR fillets (Soglia et al., 2016a, 2016b; Cai et al., 2018; Baldi et al., 2019; Madruga et al., 2019). Recently, Jarvis et al. (2020) reported that chicken patties produced using high percentages $(\geq 67 \%)$ of WB meat had higher moisture levels compared with PNOR. The aforementioned results suggest that the altered composition of raw WB meat in terms of moisture content can be reflected in WB patties. The higher moisture content could be explained by the accumulation of extracellular water because of edema and inflammatory processes caused by WB defect (Sihvo et al., 2014; Soglia et al., 2016b; Petracci et al., 2019). Certainly, a higher proportion of extra-myofibrillar water and greater mobility of intra-myofibrillar water that have been observed in WB meat (Soglia et al., 2016a; Baldi et al., 2019) might help to explain differences among chicken patty treatments in terms of moisture content.

The cooking time required for a product to achieve the target end-point temperature is also associated with the product composition and properties (Murphy et al., 2001a). In this context, the altered composition of WB meat-such as higher levels of moisture, fat, and collagen along with lower levels of protein and ash (Soglia et al., 2016a, 2016b; Baldi et al., 2019)—may have affected the cooking time of WB patties. In this vein, Marcotte et al. (2008) reported that differences in thermophysical properties of processed meat and poultry products could be related to their compositions. These authors affirmed that the thermal conductivity and diffusivity increased with moisture content, whereas these thermophysical properties decreased as the fat content increased. For example, they reported that the thermal conductivity varied between 0.272 and $0.402 \mathrm{~W} \mathrm{~m}^{-1} \mathrm{~K}^{-1}$ from $22^{\circ} \mathrm{C}$ to $79^{\circ} \mathrm{C}$ for a coarse pepperoni emulsion containing $57.26 \%$ moisture; however, the thermal conductivity varied between 0.332 and $0.482 \mathrm{~W} \mathrm{~m}^{-1} \mathrm{~K}^{-1}$ for a turkey product containing $74.88 \%$ moisture. Thus, potential alterations in thermophysical features-particularly thermal conductivity and diffusivity - caused by the WB condition could help to explain why P-SEV samples containing greater moisture levels showed shorter cooking times compared with P-NOR.

In summary, the results from the present study demonstrated that the WB condition can reduce the cooking time of chicken patties, which indicates that thermophysical properties could be altered by this myopathy. Higher levels of moisture content and cook loss that have been consistently observed in WB fillets were reflected in WB patties. In this sense, utilizing WB in these further processed products can lead to the variability of doneness of the final product, which can impact food safety and quality. Processors could unintentionally carry out an inadequate cooking process of normal products if thermal processing parameters were inadvertently monitored in WB samples. Therefore, special attention should be given to the incorporation of WB meat into poultry product formulations such as chicken patties. Future studies need to be directed toward the evaluation of cooking time of WB patties monitoring the meat particle size, preand post-grinding meat temperature, chemical composition of the product, and post-cooking temperature rise. Further research should also focus on the thermophysical properties of WB fillets and finished poultry products containing WB meat.

\section{Literature Cited}

AOAC. 2005. Official methods of analysis. 18th ed. AOAC, Gaithersburg, MD.

Baldi, G., F. Soglia, L. Laghi, S. Tappi, P. Rocculi, S. Tavaniello, D. Prioriello, R. Mucci, G. Maiorano, and M. Petracci. 2019. Comparison of quality traits among breast meat affected by current muscle abnormalities. Food Res. Int. 115:369-376. https://doi.org/10.1016/j.foodres.2018.11.020.

Baldi, G., F. Soglia, and M. Petracci. 2020a. Current status of poultry meat abnormalities. Meat Muscle Biol. 4:1-7. https://doi. org/10.22175/mmb.9503.

Baldi, G., C. N. Yen, M. R. Daughtry, J. Bodmer, B. C. Bowker, H. Zhuang, M. Petracci, and D. E. Gerrard. 2020b. Exploring the factors contributing to the high ultimate $\mathrm{pH}$ of broiler pectoralis major muscles affected by wooden breast condition. 
Front. Physiol. 11:343. https://doi.org/10.3389/fphys.2020. 00343.

Bejerholm, C., M. A. Tørngren, and M. D. Aaslyng. 2014. Cooking of meat. In: M. Dikeman, and C. Devine, editors, Encyclopedia of meat sciences. Elsevier/Academic Press, San Diego, CA. p. 370-376.

Bowker, B. C., A. D. Maxwell, H. Zhuang, and K. Adhikari. 2018. Marination and cooking performance of portioned broiler breast fillets with the wooden breast condition. Poultry Sci. 97:2966-2970. https://doi.org/10.3382/ps/pey144.

Cai, K., W. Shao, X. Chen, Y. L. Campbell, M. N. Nair, S. P. Suman, C. M. Beach, M. C. Guyton, and M. W. Schilling. 2018. Meat quality traits and proteome profile of woody broiler breast (pectoralis major) meat. Poultry Sci. 97:337346. https://doi.org/10.3382/ps/pex284.

Caldas-Cueva, J. P., and C. M. Owens. 2020. A review on the woody breast condition, detection methods, and product utilization in the contemporary poultry industry. J. Anim. Sci. 98:1-10. https://doi.org/10.1093/jas/skaa207.

Caldas-Cueva, J. P., A. Mauromoustakos, and C. M. Owens. 2020a. Instrumental texture analysis of chicken patties prepared with broiler breast fillets exhibiting woody breast characteristics. Poultry Sci. https://doi.org/10.1016/j.psj.2020.09.093.

Caldas-Cueva, J. P., C. J. Maynard, A. Mauromoustakos, and C. M. Owens. 2020b. Effect of woody breast condition on instrumental texture characteristics of poultry deli loaves. Meat Muscle Biol. 4:1-10. https://doi.org/10.22175/mmb.11223.

Chen, H., B. P. Marks, and R. Y. Murphy. 1999. Modeling coupled heat and mass transfer for convection cooking of chicken patties. J. Food Eng. 42:139-146. https://doi.org/10.1016/ S0260-8774(99)00111-9.

Chen, H., H. Wang, J. Qi, M. Wang, X. Xu, and G. Zhou. 2018. Chicken breast quality- normal, pale, soft and exudative (PSE) and woody- influences the functional properties of meat batters. Int. J. Food Sci. Tech. 53:654-664. https:// doi.org/10.1111/ijfs.13640.

Dalgaard, L. B., M. K. Rasmussen, H. C. Bertram, J. A. Jensen, H. S. Møller, M. D. Aaslyng, E. K. Hejbøl, J. R. Pedersen, D. Elsser-Gravesen, and J. F. Young. 2018. Classification of wooden breast myopathy in chicken pectoralis major by a standardised method and association with conventional quality assessments. Int. J. Food Sci. Tech. 53:1744-1752. https:// doi.org/10.1111/ijfs.13759.

Dalle Zotte, A., G. Tasoniero, E. Puolanne, H. Remignon, M. Cecchinato, E. Catelli, and M. Cullere. 2017. Effect of "wooden breast" appearance on poultry meat quality, histological traits, and lesions characterization. Czech J. Anim. Sci. 62:51-57. https://doi.org/10.17221/54/2016-CJAS.

Ferreira, V. C. S., D. Morcuende, M. S. Madruga, F. A. P. Silva, and M. Estévez. 2018. Role of protein oxidation in the nutritional loss and texture changes in ready-to-eat chicken patties. Int. J. Food Sci. Tech. 53:1518-1526. https://doi.org/10.1111/ijfs. 13733.

Isleroglu, H., T. Kemerli, Ö. Özdestan, A. Üren, and F. KaymakErtekin. 2014. Effect of oven cooking method on formation of heterocyclic amines and quality characteristics of chicken patties: Steam-assisted hybrid oven versus convection ovens. Poultry Sci. 93:2296-2303. https://doi.org/10.3382/ps.201303552.
Jarvis, T., X. Zhang, C. Rowe, B. Smith, C. Crist, and M. W. Schilling. 2020. Quality differences in traditional and clean label chicken patties formulated with woody breast meat. Meat Muscle Biol. 4:1-15. https://doi.org/10.22175/mmb. 10565.

Madruga, M. S., T. C. Rocha, L. M. Carvalho, A. M. B. L. Sousa, A. C. S. Neto, D. G. Coutinho, A. S. C. Ferreira, A. J. Soares, M. S. Galvão, E. I. Ida, and M. Estévez. 2019. The impaired quality of chicken affected by the wooden breast myopathy is counteracted in emulsion-type sausages. J. Food Sci. Tech. Mys. 56:1380-1388. https://doi.org/10.1007/s13197-019-03612-0.

Marcotte, M., A. R. Taherian, and Y. Karimi. 2008. Thermophysical properties of processed meat and poultry products. J. Food Eng. 88:315-322. https://doi.org/https:// doi.org/10.1016/j.jfoodeng.2008.02.016.

Mazzoni, M., M. Petracci, A. Meluzzi, C. Cavani, P. Clavenzani, and F. Sirri. 2015. Relationship between pectoralis major muscle histology and quality traits of chicken meat. Poultry Sci. 94:123-130. https://doi.org/10.3382/ps/peu043.

Mehaffey, J. M., S. P. Pradhan, J. F. Meullenet, J. L. Emmert, S. R. McKee, and C. M. Owens. 2006. Meat quality evaluation of minimally aged broiler breast fillets from five commercial genetic strains. Poultry Sci. 85:902-908. https://doi.org/10. 1093/ps/85.5.902.

Murphy, R. Y., E. R. Johnson, L. K. Duncan, E. C. Clausen, M. D. Davis, and J. A. March. 2001a. Heat transfer properties, moisture loss, product yield, and soluble proteins in chicken breast patties during air convection cooking. Poultry Sci. 80:508514. https://doi.org/10.1093/ps/80.4.508.

Murphy, R. Y., E. R. Johnson, L. K. Duncan, M. D. Davis, M. G. Johnson, and J. A Marcy. 2001b. Thermal inactivation of Salmonella spp. and Listeria innocua in the chicken breast patties processed in a pilot-scale air-convection oven. J. Food Sci. 66:734-741. https://doi.org/10.1111/j.1365-2621. 2001.tb04630.x.

Pathare, P. B., and A. P. Roskilly. 2016. Quality and energy evaluation in meat cooking. Food Eng. Rev. 8:435-447.

Petracci, M., F. Soglia, M. Madruga, L. Carvalho, E. Ida, and M. Estévez. 2019. Wooden-breast, white striping, and spaghetti meat: Causes, consequences and consumer perception of emerging broiler meat abnormalities. Compr. Rev. Food Sci. F. 18:565-583. https://doi.org/10.1111/1541-4337.12431.

Sanchez-Brambila, G., D. Chatterjee, B. Bowker, and H. Zhuang. 2017. Descriptive texture analyses of cooked patties made of chicken breast with the woody breast condition. Poultry Sci. 96:3489-3494. https://doi.org/10.3382/ps/pex118.

Santos, M. M. F., D. A. S. Lima, T. K. A. Bezerra, M. S. Galvão, M. S. Madruga, and F. A. P. Silva. 2019. Effect of wooden breast condition on quality traits of emulsified chicken patties during frozen storage. J. Food Sci. Tech. Mys. 56:4158-4165. https:// doi.org/10.1007/s13197-019-03886-4.

Sihvo, H. K., K. Immonen, and E. Puolanne. 2014. Myodegeneration with fibrosis and regeneration in the pectoralis major muscle of broilers. Vet. Pathol. 51:619-623. https:// doi.org/10.1177/0300985813497488.

Sihvo, H. K., J. Lindén, N. Airas, K. Immonen, J. Valaja, and E. Puolanne. 2017. Wooden breast myodegeneration of pectoralis major muscle over the growth period in broilers. Vet. Pathol. 54:119-128. https://doi.org/10.1177/0300985816658099. 
Soglia, F., L. Laghi, L. Canonico, C. Cavani, and M. Petracci. $2016 \mathrm{a}$. Functional property issues in broiler breast meat related to emerging muscle abnormalities. Food Res. Int. 89:10711076. https://doi.org/10.1016/j.foodres.2016.04.042.

Soglia, F., S. Mudalal, E. Babini, M. Di Nunzio, M. Mazzoni, F. Sirri, C. Cavani, and M. Petracci. 2016b. Histology, composition, and quality traits of chicken pectoralis major muscle affected by wooden breast abnormality. Poultry Sci. 95:651-659. https://doi.org/10.3382/ps/pev353.

Sun, X., D. A. Koltes, C. N. Coon, K. Chen, and C. M. Owens. 2018. Instrumental compression force and meat attribute changes in woody broiler breast fillets during short-term storage. Poultry Sci. 97:2600-2606. https://doi.org/10.3382/ps/pey107.

Tijare, V. V., F. L. Yang, V. A. Kuttappan, C. Z. Alvarado, C. N. Coon, and C. M. Owens. 2016. Meat quality of broiler breast fillets with white striping and woody breast muscle myopathies. Poultry Sci. 95:2167-2173. https://doi.org/10.3382/ps/pew129.

Tornberg, E. 2005. Effects of heat on meat proteins- Implications on structure and quality of meat products. Meat Sci. 70:493508. https://doi.org/10.1016/j.meatsci.2004.11.021.
Velleman, S. G. 2019. Recent developments in breast muscle myopathies associated with growth in poultry. Annu. Rev. Anim. Biosci. 7:289-308. https://doi.org/10.1146/annurev-animal020518-115311.

Wold, J. P., I. Måge, A. Løvland, K. W. Sanden, and R. Ofstad. 2019. Near-infrared spectroscopy detects woody breast syndrome in chicken fillets by the markers protein content and degree of water binding. Poultry Sci. 98:480-490. https:// doi.org/10.3382/ps/pey351.

Xing, T., X. Zhao, L. Cai, Z. Guanghong, and X. Xu. 2017. Effect of salt content on gelation of normal and wooden breast myopathy chicken pectoralis major meat batters. Int. J. Food Sci. Tech. 52:2068-2077. https://doi.org/10.1111/ijfs. 13485.

Zhang, Y., P. Wang, X. Xu, T. Xia, Z. Li, and T. Zhao. 2020. Effect of wooden breast myopathy on water-holding capacity, rheological and gelling properties of chicken broiler breast batters. Poultry Sci. 99:3742-3751. https://doi.org/10.1016/j.psj. 2020.03.032. 